\title{
A supramolecular carpet formed via self-assembly of bis(4,4'-dihydroxyphenyl) sulfone $\dagger$
}

\author{
Caitlin Davies, ${ }^{a}$ Richard F. Langler, $* a$ C. V. Krishnamohan Sharma ${ }^{b}$ and Michael J. Zaworotko*b \\ a Department of Chemistry, Mount Allison University, Sackville, New Brunswick, Canada E0A 3CO \\ ${ }^{b}$ Department of Chemistry, Saint Mary's University, Halifax, Nova Scotia, Canada B3H 3C3
}

\section{Bis(4,4'-dihydroxyphenyl) sulfone 1 exploits its tetrahed- rally disposed complementary hydrogen bonding sites to generate a unique doubly interwoven molecular carpet architecture in the solid state.}

The concept of rational design of 2D and 3D frameworks has evoked considerable interest in recent years as many functional properties of solids are dependent on crystal packing. ${ }^{1,2} \mathrm{~A}$ particularly interesting and relevant problem that has been addressed by several groups concerns the preparation of open cage and/or interwoven networks. ${ }^{3-5}$ While the former is desired in the context of porous solids, the latter is an associated phenomenon which invariably occurs if $>50 \%$ of a solid would otherwise be empty. Such interpenetration (or catenation) is appreciated for its aesthetic appeal and offers potential host materials if guest molecules can be exploited to prevent interpenetration. ${ }^{6}$ Understanding and predicting interpenetration patterns therefore constitutes an important aspect of crystal engineering.

Self-assembly can be an effective strategy for crystal engineering but it requires careful control over molecular symmetry and functionality. ${ }^{3}$ In general, tetrahedral molecules with rigid complementary hydrogen bonding sites adapt diamondoid architecture with levels of interpenetration based on the relative size of superdiamondoid cage and the volume of the tecton. ${ }^{7}$ We report herein an alternate motif for such compounds which occurs if there is flexibility present in the tecton: interwoven 2D square grids. ${ }^{8}$

A solution of bis(4-chlorophenyl) sulfone ( $4.0 \mathrm{~g})$ and sodium hydroxide $(4.0 \mathrm{~g})$ in $\mathrm{Me}_{2} \mathrm{SO}(160 \mathrm{ml})$ and water $(40 \mathrm{ml})$ was maintained at $100{ }^{\circ} \mathrm{C}$ for two months. Extractive workup with diethyl ether furnished a mixture of unchanged chloro sulfone, bis(4-hydroxyphenyl) sulfone $\mathbf{1}$ and 4-chlorophenyl (4'-hydroxyphenyl) sulfone 2 . Chloroform elution on silica gel furnished pure $\mathbf{1}(2 \%)$ and $2(50 \%)$.

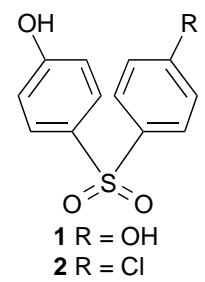

Non-centrosymmetric crystals of $\mathbf{1}$ were obtained from acetone- $\mathrm{CHCl}_{3}$ (mp 247-249 ${ }^{\circ} \mathrm{C}$ ). The crystal structure $\$$ reveals an infinite $2 \mathrm{D}$ hydrogen bonded network sustained by interaction between hydroxy and sulfone groups $(\mathrm{O} \cdots \mathrm{O}$ 2.705(7), 2.800(3) ^, Fig. 1). The network generates square cavities with ca. $8 \times 10 \AA$ dimensions, large enough to facilitate generation of a 2-fold interwoven molecular carpet (Fig. 2). The entangled 2D grids are stabilized by van der Waals and herringbone interactions. A 3D diamondoid architecture is also feasible but presumably packs less efficiently in the absence of an appropriate guest.
The molecular carpet architecture of $\mathbf{1}$ demonstrates how molecules with flexible hydrogen bonding sites can selfassemble to yield 2D interwoven networks as an alternative to 3D diamondoid architectures. Such networks would be expected to have clay-like intercalation properties and, if appropriate guests can be used to eschew interpenetration, large cavities within the grid. 9 The critical importance of complementarity amongst the hydrogen bonding sites is illustrated by what happens if one hydroxy substituent of $\mathbf{1}$ is replaced by a chloro substituent. 4-chlorophenyl (4'-hydroxyphenyl) sulfone 2 exhibits a less predictable but nonetheless intriguing crystal structure. $\S$ Compound 2 crystallizes from $\mathrm{CHCl}_{3}(\mathrm{mp}$ $150-151^{\circ} \mathrm{C}$ ) in the non-centrosymmetric space group $P 1$ with, remarkably, four molecules in the asymmetric unit. There are two discrete hydrogen bonding motifs: i, simple linear hydrogen bonding between sulfone and hydroxy groups [2.898(6) A]]; ii, cyclic hydrogen bonding involving two of the sulfone $\mathrm{O}$ atoms and three hydroxy groups, possibly with two of the hydroxy groups being disordered [Scheme 1, O‥O: 2.838(6), 2.881(6),

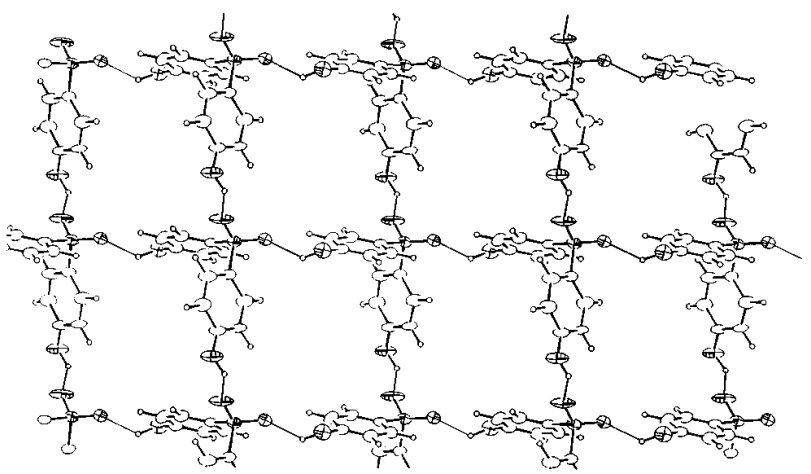

Fig. 1 ORTEP diagram of $\mathbf{1}$ illustrating a single hydrogen bonded network

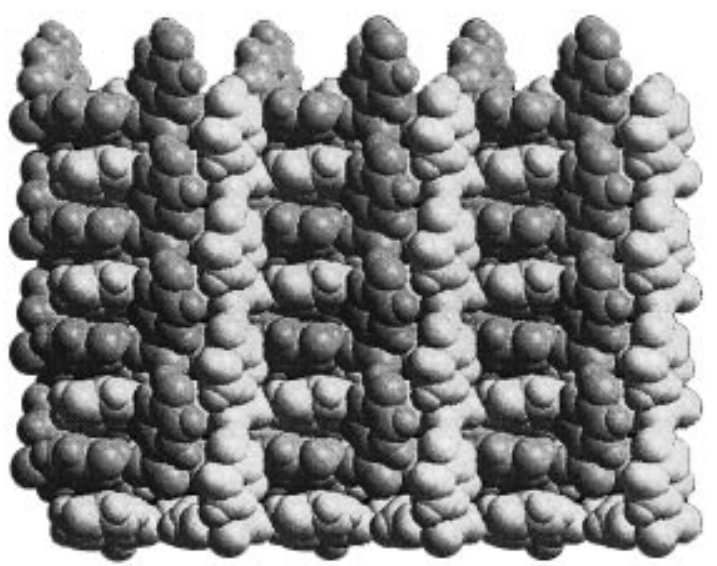

Fig. 2 A space filling diagram of the interwoven supramolecular carpet architecture of $\mathbf{1}$. The two independent grids are colour coded for clarity. 
<smiles>CCOOOP(C)(C)(C)OC</smiles>

Scheme 1

3.019(6), 2.913(6) ̊]. Furthermore, there are two different kinds of aryl-aryl stacking interactions: between chlorophenyl and hydroxyphenyl groups and between adjacent chlorophenyl groups. The mean interplanar distances and dihedral angles of these two stacking interactions are 3.74 and $3.60 \AA, 2.9$ and $3.4^{\circ}$ respectively.

Compounds 1 and 2 illustrate clearly the importance of selfassembly to crystal engineering. Compound $\mathbf{1}$ demonstrates how tetrahedral moieties with complementary hydrogen bonding sites are capable of self-assembling into a predictable 2D motif if the hydrogen bonding sites are robust and flexible. However, 2 demonstrates how even minor changes in functionality can lead to unusual and unpredictable crystal packing.

\section{Footnotes}

$\dagger$ This ChemComm is also available in enhanced multi-media format $v i a$ the World Wide Web: http://chemistry.rsc.org/rsc/cccenha.htm

+ Crystal Data for 1: 4,4'-Dihydroxyphenyl sulfone, $M=249.26$ orthorhombic, $C 2 c b, a=8.1572(10), b=19.2757(21), c=15.0471(20)$ $\AA, V=2365.9(5) \AA^{3}, Z=8, D_{\text {calc }}=1.40 \mathrm{Mg} \mathrm{m}^{-3}, \lambda=0.70930 \AA$ $F(000)=1032.921$ reflections with $I_{\text {net }}>3 \sigma\left(I_{\text {net }}\right)$ out of 1121 unique reflections measured at $290 \mathrm{~K}$ for a crystal of dimensions $0.3 \times 0.2 \times 0.4$ $\mathrm{mm}$ on an Enraf-Nonius CAD4 diffractometer using the $\omega$ scan mode $4<$ $2 \theta<50^{\circ}$ ) afforded, on convergence, final values of $R_{\mathrm{f}}=0.077$ and $R_{\mathrm{w}}=0.089$. The $\mathrm{H}$ atom of one of the two $\mathrm{OH}$ groups was found via difference Fourier map inspection. Other $\mathrm{H}$ atoms were placed in calculated positions $(\mathrm{C}-\mathrm{H}=1.0 \AA)$. All non-hydrogen atoms were anisotropically refined. The crystallographic calculations were carried out using NRCVAX program package. Atomic coordinates, bond lengths and angles, and thermal parameters for both $\mathbf{1}$ and $\mathbf{2}$ (see below) have been deposited at the Camrbidge Crystallograpic Centre (CCDC). See Information for Authors, Issue No. 1 . Any request to the $\mathrm{CCDC}$ for this material should quote the full literature citation and the reference number 182/360.
Since submission of this article an account of the structure of $\mathbf{1}$ has been published. See G. Ferguson and C. Glidewell, Acta Crystallogr., Sect. C, 1996, 52, 2528.

$\S$ Crystal Data for 2: As for 1 but 4-hydroxyphenyl, 4'-chlorophenyl sulfone, $M=267.96$, triclinic, $P 1, a=7.6401(11), b=9.2850(11)$, $c=17.6630(13) \AA, \alpha=93.04(2), \beta=91.51(3), \gamma=108.64(2)$, $V=1184.35(24) \AA^{3}, Z=4, D_{\text {calc }}=1.503 \mathrm{Mg} \mathrm{m}^{-3}, \lambda=0.70930 \AA$ $F(000)=552.3591$ reflections with $I_{\text {net }}>3 \sigma\left(I_{\text {net }}\right)$ out of 4149 unique reflections measured at $290 \mathrm{~K}$ for a crystal of dimensions $0.4 \times 0.2 \times 0.2$ $\mathrm{mm}$ afforded values of $R_{\mathrm{f}}=0.042$ and $R_{\mathrm{w}}=0.047$.

\section{References}

1 G. R. Desiraju, Crystal Engineering: The Design of Organic Solids, Elsevier, Amsterdam, 1989.

2 B. F. Abrahams, B. F. Hoskins and R. Robson, J. Am. Chem. Soc., 1991, 113, 3603 .

3 M. J. Zaworotko, Chem. Soc. Rev., 1994, 283.

4 G. B. Gardner, D. Venkataraman, J. S. Moore and S. Lee, Nature, 1995, 374, 792; O. M. Yaghi, G. Li and H. Li, Nature, 1995, 378, 703; M. E. Brown and M. D. Hollingsworth, Nature, 1995, 376, 323; S. V. Kolotuchin, E. E. Fenlon, S. R. Wilson, C. J. Loweth and S. C. Zimmerman, Angew. Chem., Int. Ed. Engl., 1995, 34, 2654; S. Subramanian and M. J. Zaworotko, Angew. Chem., Int. Ed. Engl., 1995, 34, 2127; M. Munakata, L. P. Wu, M. Yamamoto, T. Kuroda-Sowa and M. Maekawa, J. Am. Chem. Soc., 1996, 118, 3117.

5 D. B. Amabilino and J. F. Stoddart, Chem. Rev., 1995, 95, 2725; D. S. Reddy, D. C. Craig, A. D. Rae and G. R. Desiraju, J. Chem. Soc., Chem. Commun., 1994, 1457; D. M. Goodgame, S. Menzer, A. M. Smith and D. J. Williams, J. Chem. Soc., Chem. Commun., 1995, 1975; L. Carlucci, G. Ciani, D. M. Proserpio and A. Sironi, J. Chem. Soc., Chem. Commun., 1994, 2755; P. M. V. Calcar, M. M. Olmstead and A. Balch, J. Chem. Soc., Chem. Commun., 1995, 1723; L. R. MacGillivray, S. Subramanian and M. J. Zaworotko, J. Chem. Soc., Chem. Commun., 1994, 1325.

6 F. H. Herbstein, M. Kapon and G. M. Reisner, J. Inclusion Phenom., 1987, 5, 211.

7 O. Ermer, J. Am. Chem. Soc., 1988, 110, 3747; O. Ermer, Angew. Chem. Int. Ed. Engl., 1988, 27, 829; X. Wang, M. Simard and J. D. Wuest, J. Am. Chem. Soc., 1994, 116, 12119.

8 Supramolecular carpets from multiple components were reported by us earlier: S. B. Copp, S. Subramanian and M. J. Zaworotko, Angew. Chem., Int. Ed. Engl., 1993, 32, 706; C. V. K. Sharma and M. J. Zaworotko, Chem. Commun., 1996, 2655. Related coordination polymers have also been encountered: D. M. L. Goodgame, S. Menzer, A. M. Smith and D. J. Williams, Angew. Chem., Int. Ed. Engl., 1995, 34, 574.

9 A. Muller, H. Reuter and S. Dillinger, Angew. Chem., Int. Ed. Engl., 1995, 34, 2328; S. B. Copp and M. J. Zaworotko, unpublished results.

Received, 17th May 1996; Revised manuscript received, 15th January 1997; Com. 7/00363C 